\title{
Editorial: IMC's Fuzzy Picture: Breakthrough or Breakdown?
}

WILLIAM A. COOK

Guest Editor

SVP Research, The ARF

Bill.Cook@TheARF.org
Integrated Marketing Communications (IMC) was a breakthrough concept when Don Schultz introduced it to marketers in the 1980s. But IMC, which is even more important today as the "marketing mix" has expanded to include many nontraditional activities, has had trouble moving from concept to practical application.

Marketers today still ask, "Do I have an effective integrated marketing plan? Can I measure the ROI for each medium I am using (traditional and nontraditional) ... has anybody ever measured the ROI of sports sponsorship?" Many of the articles in this issue are directed at advancing this important dialogue.

Since IMC extends beyond traditional media and marketing tools and involves processes that are in transition, the challenge of finding conceptual footing and directional guidance from research looms larger than in traditional marketing. After over a decade of growth, IMC can hardly be considered a "management fad," as some have questioned in pages of this journal over that period (Cornelissen and Lock, 2000). However, we can make out only a fuzzy image of what IMC "will be when it grows up."

Coming into focus in this issue are several useful points of reference that you may find will sharpen your definition and application of IMC in future dialogue and research. Swain's article underscores the worth of talking to multiple constituencies when assessing the value of IMC. Gould urges that, "More thought and research should be devoted to the discourse and thinking of practitioners in various areas, such as advertising and public relations, to map and triangulate their views." Kitchen et al. point out that to accomplish truly integrated marketing a business has to shift from "talking the talk" to "walking the walk" - a commitment that requires organizational change and added resources. Kim, Han, and Schultz in their article remind us of the importance of ap- proaching IMC from a global perspective. Gould, too, pushes for a Global IMC perspective.

Since the early 1990s the IMC concept has grown in influence and scope. The "Integrated" in IMC today has a deeper and a broader meaning than it did in the early 1990s. Initially, "integrated" referred primarily to coordinated marketing efforts; then the notion of harmonious activities took center stage with the tighter focus on "one voice" and coherent planning. Today there is an added dimension to the meaning of integrated in the way the IMC concept is discussed and applied, completeness or "holistic" as Jim Stengel describes it.

Completeness leaps out from our lead article in this issue by Zahay, Peltier, Schultz, and Griffin. The walls of the silos separating sales and marketing have not crumbled, but I see encouraging openings revealed in Zahay et al.'s assessment of the contributions to companies' marketing and sales performances from their transactional and relationship-supporting databases. It is especially useful for researchers to identify constructs that enable us to picture the very real world of businessto-business marketing through the lens of IMC theory yielding some very practical views.

Real answers, if not real breakthroughs, are packed into the articles here. I think that IMC has the potential for breakthrough contributions when marketers advance their IMC programs to the "Financial and Strategic Integration" stage articulated by Schultz and Kitchen (2000) and reiterated in this issue by Kitchen et al.

Over the last few years, integrated marketing has gained momentum from the rapid evolution of the internet and the technological advances in coupling database systems. There is growing recognition that media databases can offer improved targeting potential as has been expected from marketing databases. Marketers that seek to link media and marketing databases are likely to gain a fuller recognition of the customer and to bring 
IMC full circle-to incorporate both creative strategy and media planning.

Please don't read the articles in this issue. Torture the articles in this issue. Hammer them with the questions that you are asked when you speak with marketers about IMC. You will find answers here. Add some follow through, and create your own breakthrough.

JAB

\section{REFERENCES}

Cornelissen, Joep P., and Andrew R. Lock.

"Theoretical Concept or Management Fashion?
Examining the Significance of IMC." Journal of Advertising Research 40, 5 (2000): 7-15.

Schultz, D. E., and P. J. Kitchen. Communicating Globally: An Integrated Marketing Approach. London: Macmillan Press Ltd., 2000. 